\title{
Pattern of chronic urticaria and value of autologous serum skin test in Sohag Province, Upper Egypt
}

Reham Ezz El-Dawla El-Sharkawy ${ }^{1}$, Wafaa Mohamed Abd-Elmaged², Doaa Anwar Ahmed³, Sahar Abo ElFetoh Abdel-Wahed ${ }^{4}$

${ }^{1}$ Assistant Professor, Dermatology and Venereology Department, Faculty of Medicine, Sohag University, Sohag, Egypt

${ }^{2}$ Lecturer, Dermatology and Venereology Department, Faculty of Medicine, Sohag University, Sohag, Egypt

${ }^{3}$ Resident at Dermatology Department, Sohag General Hospital, Sohag, Egypt

${ }^{4}$ Assistant Professor, Clinical Pathology Department, Faculty of Medicine, Sohag University, Sohag, Egypt

Type of article: Original

\begin{abstract}
Background: Chronic urticaria (CU) is a debilitating disorder with variable clinical course. It is characterized by hives occurring for at least 6 weeks, and is classified as spontaneous or inducible.

Objective: The aim of this study was to detect the pattern of $\mathrm{CU}$, to study association between results of autologous serum skin test (ASST) and urticaria severity score (USS), and to detect serum levels of anti IgE receptors antibodies.

Methods: This study included all patients attending the Dermatology Outpatient Clinic, Sohag University Hospital, who were diagnosed as CU from April 2015 to March 2016. ASST and serum level of anti IgE receptor antibodies was assessed using ELISA. Data were analyzed by SPSS version 16, using descriptive statistics, Kruskal-Wallis and Mann-Whitney U test.

Results: A total of 108 patients with CU were included in the study. Females with mean age $33 \pm 12.4$ years were more affected. A total of $58.3 \%$ complained of CSU, $6.5 \%$ physical urticaria and $35.2 \%$ mixed type of CU. According to USS, mild score represented $20.4 \%$, moderate $46.3 \%$ and severe in $33.3 \%$. ASST showed positive in $38 \%$ of patients. There was a statistically significant relation between ASST and USS and duration of CU. This indicates that more severe symptoms and prolonged duration of CU are observed in positive ASST (autoreactive type). In all, $91 \%$ of the anti IgE receptor antibodies positive patients had positive ASST.

Conclusion: In conclusion, chronic urticaria is not an uncommon disease in our locality which represented $1.13 \%$ of our patients. Urticaria severity score and duration of urticaria was higher in positive ASST patients and hence the autoreactive type.
\end{abstract}

Keywords: Severity score, Skin test, Urticaria

\section{Introduction}

Chronic urticaria (CU) is a skin disorder characterized by transient pruritic wheals that recur from day to day for 6 weeks or more. Females are affected nearly twice as often as males, and the peak age of manifestation of CU is 20 40 years (1). The incidence of CU has been estimated at $1.4 \%$ per year in the USA (2). It is divided into chronic spontaneous (CSU) and inducible urticaria (3), Chronic inducible urticaria is defined when a trigger can be identified (4). In CSU, the appearance of lesions is not triggered by consistent or identifiable factors, and it specifically excludes physical urticaria syndromes. It accounts for approximately two-thirds of all cases of CU. CSU is classified into 2 subtypes including chronic autoreactive and idiopathic urticaria (5). The most severe form of CU is autoreactive chronic urticaria (ACU) and it is associated with presence of circulating histamine-releasing autoantibodies, specifically directed against IgE high-affinity receptors (FceRI $\alpha$ ) that are present in the cytoplasmic membrane of mast cells and basophils or anti-IgE autoantibodies (6). The autologous serum skin test (ASST) can

\section{Corresponding author:}

Wafaa Mohamed Abd-Elmaged, Dermatology and Venereology Department, Faculty of Medicine, Sohag University, Sohag, Egypt.

Tel.: +20.1008813349; Fax: +20.934602963, E-mail: wafaa_Mohamed@med.sohag.edu.eg

Received: February 24, 2018, Accepted: March 28, 2018, Published: May 2018

iThenticate screening: March 05, 2018, English editing: April 10, 2018, Quality control: April 15, 2018

(C) 2018 The Authors. This is an open access article under the terms of the Creative Commons Attribution-NonCommercialNoDerivs License, which permits use and distribution in any medium, provided the original work is properly cited, the use is non-commercial and no modifications or adaptations are made. 
assess autoreactivity in ACU patients. It can be identified as mast cell-activating autoantibodies that act either indirectly through the release of mediators from cutaneous mast cells and a number of other cells, or act directly in the microvasculature of the skin (7). The test is a simple in-vivo clinical test which detects basophil histamine releasing activity (8). Autoreactive $\mathrm{CU}$ has been associated with autoimmune conditions, such as the presence of elevated thyroid autoantibodies, type 1 diabetes mellitus (9), rheumatoid arthritis, Sjogren syndrome, celiac disease, and systemic lupus erythematosus (10). Chronic idiopathic urticaria (CIU) is the CU with no obvious cause, patients with CIU do not have evidence of autoimmunity. There is persistent activation of mast cells, but the mechanism of mast cell triggering is unknown (11). The aim of this study was to detect the pattern of CU among the patients attending our outpatient clinic, also to study the association between the results of autologous serum skin test (ASST) and urticaria severity score (USS), and to detect serum levels of anti IgE receptors antibodies using ELISA.

\section{Material and Methods}

\subsection{Study design and population}

This cross sectional study included all patients attending the Dermatology Outpatient Clinic, Sohag University Hospital, who were diagnosed as CU from April 2015 to March 2016.

\subsection{Selection criteria}

The study included all cases of $\mathrm{CU}$, both sexes, aged from 15-70 years old. Exclusion criteria were pregnant and lactating women, patients aged less than 15 and more than 70 years old, and patients complaining of angioedema without wheals and urticarial vasculitis.

\subsection{Study steps}

Complete history was taken from each patient: systemic symptoms and history of atopia, past history of similar condition or drug intake, family history, and autoimmune diseases. Urticarial severity was assessed for each patient using urticaria severity score. The severity score was divided into mild $(\leq 5)$, moderate (6-10), and severe (>10) (12). General and dermatological examination was done for each patient, laboratory tests included complete blood count, liver and renal function, ESR, urine and stool analysis, total T3 and T4 level, helicobacter pylori antigen and antibody titer for hepatitis B and C virus. Autologous serum skin test was done. Patients were required to be off antihistamines treatment for at least 3 days and corticosteroids and other immunosuppressive drugs for 4 weeks before the study, to reduce the possibility of generating false-negative results (7). Venous blood samples of $5 \mathrm{ml}$ were collected in sterile plain tubes without a clotting accelerator, and were allowed to clot for $30 \mathrm{~min}$ at room temperature. After $15 \mathrm{~min}$ centrifugation at $2000 \mathrm{rpm}$, samples of $0.05 \mathrm{ml}$ of autologous serum and $0.9 \%$ sterile normal saline were separately injected intradermally into the volar aspect of the right forearm with a $5 \mathrm{~cm}$ gap between injection sites. Wheal and flare response was measured at $30 \mathrm{~min}$. ASST was recorded as positive if a serum-induced wheal which was both red and with its diameter larger than a saline-induced response by $\geq 1.5 \mathrm{~mm}$ was seen at $30 \mathrm{~min}$ (8). To confirm the autoreactivity of $\mathrm{CU}$, serum level of anti immunoglobulin E receptor antibody was assessed using ELISA method (Kit provided by Glory Science Co., Ltd, USA.CATALOG \#: 12252), allowing for the in vitro quantitative determination of anti-IgE receptor antibody concentrations in serum of the patients.

\subsection{Statistical analysis}

Data were analyzed using SPSS version 16.0 (SPSS Inc., Chicago, Illinois, USA). The data were tested for normality using Kolmogorov-Smirnov, and Shapiro-Wilk tests which were significant indicating the use of nonparametric tests as data was not normally distributed. Chi-square test was used for comparison regarding qualitative variables. The non-parametric Mann-Whitney $U$ test was used for comparing two quantitative variables. KruskalWallis test was used for comparison between more than two quantitative variables. P-value $\leq 0.05$ was considered significant.

\subsection{Ethics}

The study was submitted for approval by the Research and Ethical Committee at the faculty. Written informed consent was obtained from each patient.

\section{Results}

\subsection{General findings}

A total of 108 patients with $\mathrm{CU}$ were included in the study. They composed $1.13 \%$ of a total 9,600 patients who attended the dermatology clinic at our hospital from April 2015 to March 2016. The mean age of the patients was $33 \pm 12.4$ years. Eighty five patients $(78.7 \%)$ were females, with male to female ratio at $1: 3.7$. Their socio demographic characteristics were demonstrated in Table 1. 
Table 1. Sociodemographic characteristics of the study group $(n=108)$

\begin{tabular}{|l|l|l|}
\hline \multicolumn{2}{|l|}{ Socio demographic characteristics } & $\mathrm{n}(\%)$ \\
\hline Age (year) (Mean $\pm \mathrm{SD}=33 \pm 12.4)$ & $15-20$ & $18(16.7)$ \\
\cline { 2 - 3 } & $20-40$ & $55(50.9)$ \\
\cline { 2 - 3 } & $40-60$ & $32(29.6)$ \\
\cline { 2 - 3 } & $>60$ & $3(2.8)$ \\
\hline \multirow{2}{*}{ Gender (Female/ male ratio =3.7) } & Female & $85(78.7)$ \\
\cline { 2 - 3 } & Male & $23(21.3)$ \\
\hline \multirow{2}{*}{ Residence } & Rural & $56(51.9)$ \\
\cline { 2 - 3 } & Urban & $52(48.1)$ \\
\hline \multirow{5}{*}{ Sarital Status } & Married & $74(68.6)$ \\
\cline { 2 - 3 } & Single & $28(25.9)$ \\
\cline { 2 - 3 } & Widow & $5(4.6)$ \\
\cline { 2 - 3 } & Divorced & $1(0.9)$ \\
\hline Occupation & Smoker & $11(10.8)$ \\
\cline { 2 - 3 } & Non Smoker & $97(89.8)$ \\
\hline & House Wife & $67(62)$ \\
\cline { 2 - 3 } & Manual Worker & $21(19.4)$ \\
\cline { 2 - 3 } & Officer & $12(11.2)$ \\
\cline { 2 - 3 } & Student & $8(7.4)$ \\
\hline
\end{tabular}

\subsection{The characteristics of chronic urticaria}

A total of 63 patients (58.3\%) had CSU, seven patients (6.5\%) had physical urticaria and 38 patients (35.2\%) had mixed type of CU. The mean duration \pm SD was $3.1 \pm 3.87$ years. In all, 57 of the patients $(52.8 \%)$ had angioedema and wheals and $51(47.2 \%)$ had wheals only. Only 7 of the patients $(6.5 \%)$ were H pylori antigen positive but 5 of them $(4.7 \%)$ had thyroid disease, $8(7.4 \%)$ were hepatitis $\mathrm{C}$ positive, one $(0.9 \%)$ was positive for hepatitis B surface antigen and a majority of $80(74.1 \%)$ had normal laboratory findings, and urticarial symptoms were exacerbated in $35(32.4 \%)$ due to NSAID intake patients. The most common aggravating factors for urticarial symptoms were stress 53 (49\%), followed by sun exposure $28(25.9 \%)$ and food $27(25 \%)$.

\subsection{Autologous serum skin test (ASST)}

Regarding ASST, it was positive in $41(38 \%)$ patients (Figures 1, 2). There was a statistically significant relation between ASST result and duration of the disease $(\mathrm{p}=0.014)$ as shown in Table 2 . But no statistically significant relation between ASST and age of the patients or the type of $\mathrm{CU}$ ( $\mathrm{p}=0.403, \mathrm{p}=0.081$ respectively).

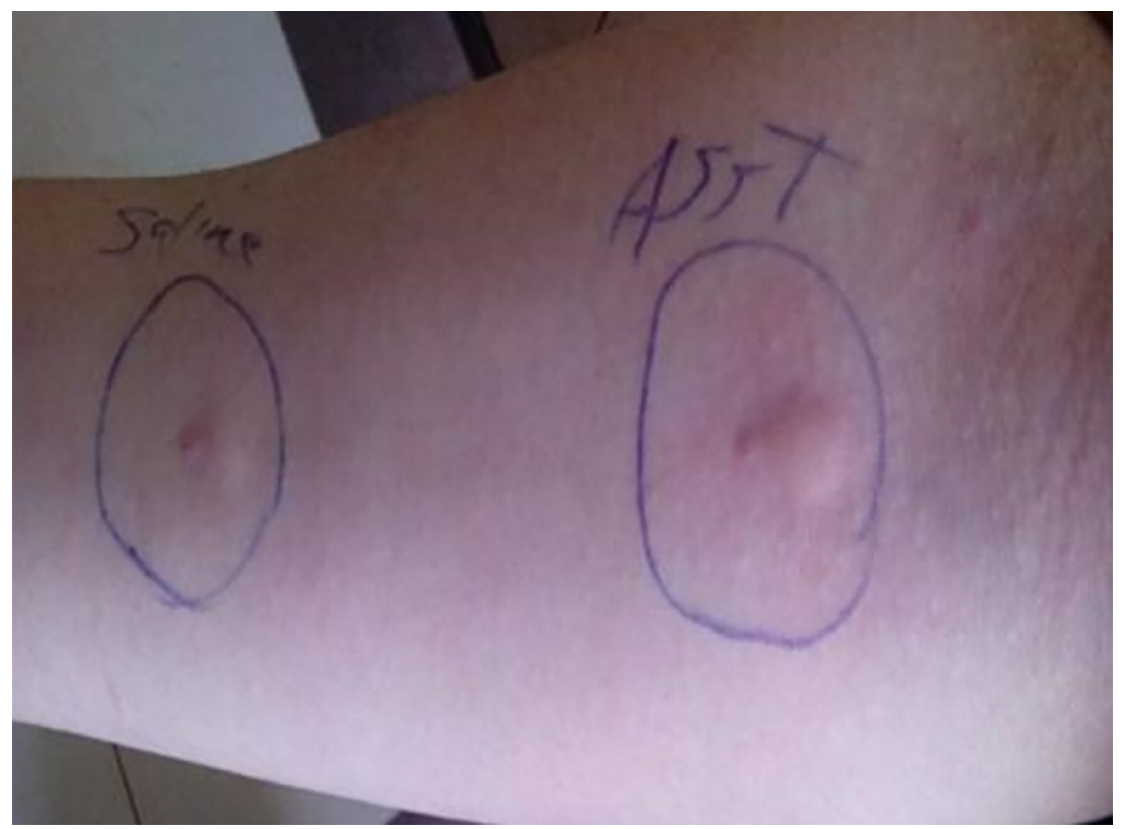

Figure 1. Positive ASST. 


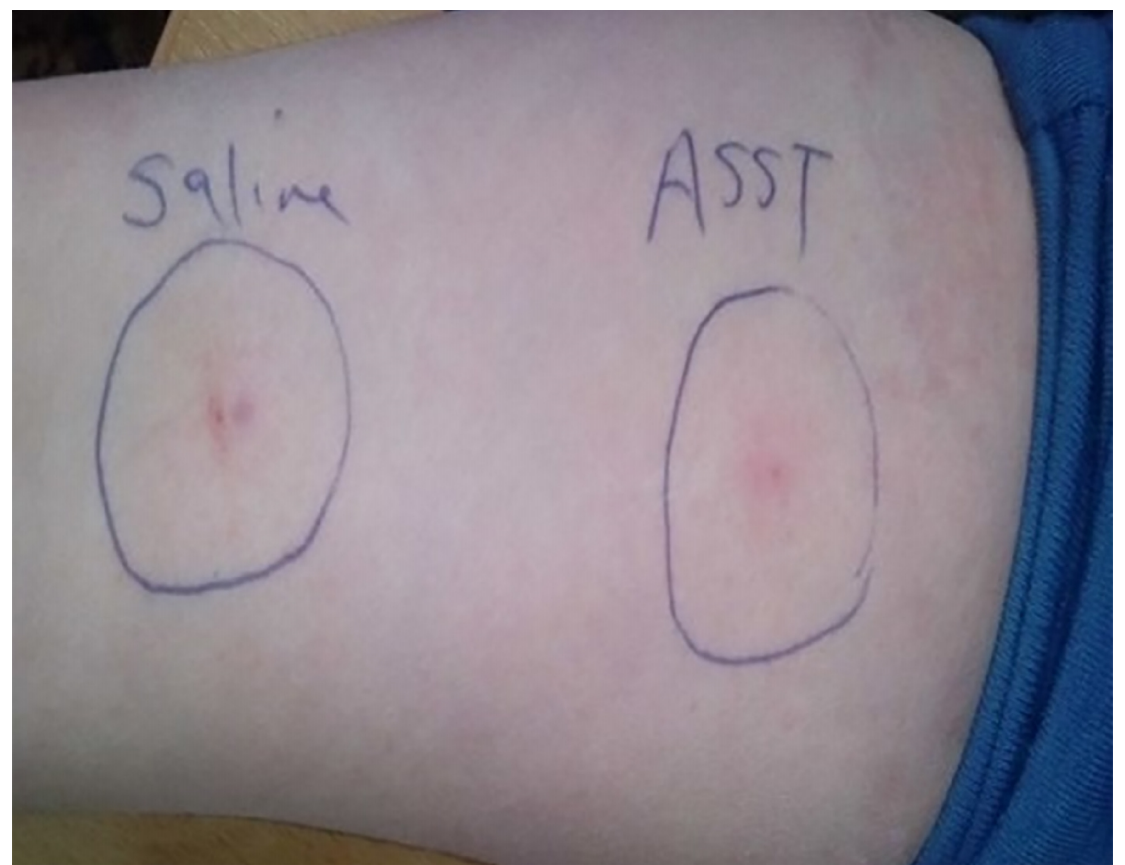

Figure 2. Negative ASST.

Table 2. The relation of ASST to the duration of disease group $(n=108)$

\begin{tabular}{|l|l|l|l|}
\hline Duration of disease & Positive ASST; $\mathrm{n}(\%)$ & Negative ASST; $\mathrm{n}(\%)$ & Total; $\mathrm{n}(\%)$ \\
\hline$<1$ year & $6(17.1)$ & $29(82.9)$ & $35(100.0)$ \\
\hline $1-5$ years & $23(44.2)$ & $29(55.8)$ & $52(100.0)$ \\
\hline $5-10$ years & $6(60)$ & $4(40)$ & $10(100.0)$ \\
\hline$\geq 10$ years & $6(54.5)$ & $5(45.5)$ & $11(100.0)$ \\
\hline Total & $41(38)$ & $67(62)$ & $108(100.0)$ \\
\hline$\chi^{2}=10.65, p=0.014 *$ & $*$ Chi square test
\end{tabular}

\subsection{Urticaria severity score (USS)}

With regard to USS, $22(20.4 \%)$ of the patients had mild score, 50 (46.3\%) moderate score and $36(33.3 \%)$ severe score. The relation of USS to the positivity of ASST was statistically significant $(\mathrm{p}=0.000)$ as shown in Table 3 .

Table 3. The relation of ASST to each score group $(n=108)$

\begin{tabular}{|l|l|l|l|}
\hline The score & Positive ASST; $\mathrm{n}(\%)$ & Negative ASST; $\mathrm{n}(\%)$ & Total; $\mathrm{n}(\%)$ \\
\hline$\leq 5($ mild $)$ & $0(0)$ & $22(100)$ & $22(100.0)$ \\
\hline 6 to $10($ moderate) & $12(24)$ & $38(76)$ & $50(100.0)$ \\
\hline$>10($ severe) & $29(80.6)$ & $7(19.4)$ & $36(100.0)$ \\
\hline Total & $41(38)$ & $67(62)$ & $108(100.0)$ \\
\hline$\chi^{2}=45.33, \mathrm{p}=0.000 *$ \\
\hline
\end{tabular}

\subsection{Serum level of anti IgE receptor antibodies}

The normal detection range of anti IgE receptor antibodies in the serum is 7-200 ng/ml. In the present study, those antibodies were searched for in 83 patients. It was found that 33 (39.8\%) of those patients had positive antibodies but $50(60.2 \%)$ had negative ones. The majority (90.9\%) of the antibody positive patients had positive ASST compared to those who had negative ASST (9.1\%), which was statistically significant $(\mathrm{p}=0.000)$. The mean of anti IgE receptor antibodies in the ASST positive group was more than that of the negative one, $(28.72 \pm 43.6 \mathrm{ng}$ versus $2.79 \pm 1.19 \mathrm{ng})$ that was highly significant $(\mathrm{p}<0.001)$. But there was no statistically significant relation between the level of these antibodies and age of patients, type of CU and duration of the disease $(p=0.383, p=0.472$, and $p=0.212$ respectively). 


\section{Discussion and conclusions}

Chronic urticaria (CU) is a skin disorder characterized by the recurrent appearance of wheals and/or angioedema for at least 6 weeks. $\mathrm{CU}$ is a heterogeneous disorder which includes chronic spontaneous urticaria (CSU) and chronic inducible urticaria (CIU) (13). Our study included 108 patients complaining of chronic urticaria. They represented $1.13 \%$ of the total of patients who attended the dermatology clinic at Sohag University Hospital from April 2015 to March 2016. This result is similar to that stated by Abd El-Azim and Abd El-Azim (7) that chronic urticaria affected up to $1 \%$ of the general population. Eighty five patients $(78.7 \%)$ were females, with male to female ratio at $1: 3.7$. So there is a female predominance similar to previous studies $(8,14)$. The reasons for these sex-related differences are not completely understood. A possible explanation may be the autoimmune nature of the disease, at least in a subgroup of patients with CSU (15). In the current study the mean age of the patients is $33 \pm 12.4$ years. This result is comparable to a study done by Lee et al. (16) from Taiwan who found that the mean age was 31.8 \pm 10.4 . Another study by Choi et al. (17) from Korea found that the mean age is older and was $40.8 \pm 10.6$ years. The peak age of chronic urticaria patients is between 20 and 40 years in most studies. This means that patients are primarily affected during important years of their working age. The present study showed that mean of duration of chronic urticaria is 3.1 \pm 3.87 years. This is in consistent with a study done by Abd El-Azim and Abd El-Azim (7) who found the mean duration of chronic urticaria was $2.2 \pm 2.5$ years. In contrast to a study done by Heng et al. (18), in which the mean duration of complaint ranged from 1.5 months up to 10 years. This means that duration of chronic urticaria varies widely among different populations and from one person to another in the same population. In the present study $52.8 \%$ of the patients have associated angioedema that is near to the finding of Vikram Kumar et al. (19) who found that $66 \%$ of the patients had associated angioedema. This was higher than other studies $(7,8)$. These differences indicate variation of incidence of angioedema that is associated with chronic urticaria of unknown cause. In this study, 63 of the patients $(58.3 \%)$ complained of CSU, 7 (6.5\%) of the patients complained of physical urticaria and $38(35.2 \%)$ complained of mixed type of chronic urticaria. In another study done by Ue et al. (20), the percentages were $23.3 \%, 27.4 \%$, and $40.3 \%$ respectively. Dermographism was present in 39 patients (36\%) either alone or in association with chronic spontaneous urticaria that is concurrent with a study done by Abd El-Azim et al. (21). This explains that symptomatic dermographism represents the most common type of physical chronic urticaria. Ten percent of the patients in this study had an urticarial wheal concomitantly with atopic symptoms. These were suspected of being an IgE-mediated mechanism. Previous study done by Vichayanond et al. (22) revealed little evidence to suggest that allergy is an important factor in CU. However, allergy is more important in acute urticaria than chronic urticaria. Various infections have been reported to be the associating factors of CU including parasitic infection, hepatitis and H. pylori infection. In this study, $6.5 \%$ of the patients were positive for helicobacter pylori antigen, which is in contrast to a study done by Yadav et al. (23) from India, in which 70.5\% of patients were positive for this finding. Such different results could be explained by differences in the antigenicity or biological activity of the bacteria (HP) in different areas, with different socio-economic and genetical patterns of the host population (24). H. pylori can have an indirect involvement in the etiology of CU, by reducing the immune tolerance and inducing the formation of autoantibodies, including the production of autoantibodies to anti-FceRI $\alpha$ (25). In this study, $7.4 \%$ and $0.9 \%$ of the patients are hepatitis $\mathrm{C}$ and hepatitis B positive respectively in contrast to a study done by Bhatt (26) in which $2.8 \%$ of the patients were seropositive for HBsAg and none for the anti-HCV. Another study done by Malik et al. (27) showed that $1.1 \%$ of patients of chronic urticaria had anti-HCV antibody. Parasitic infestation was present in $4.6 \%$ of our patients. This was less than that of a study done in 2012 by Dilek et al. (28) in which $38.8 \%$ of the patients had parasitic infestation in association with chronic urticaria. In previous studies, the urticarial symptoms did not improve or were not completely cured after treatments of parasitic infestations, this implied that these might be co-incidental symptoms. In the current study, five patients (4.7\%) had thyroid disease. Confino-Cohen et al. (10) reported a higher percentage of thyroid problems in their study $(9.8 \%)$. Both indicate the association of chronic urticaria to thyroid disease. This may explain the coexistence of autoantibodies in both (antithyroid peroxidase antibodies and IgE receptor antibodies) because of B-cell hyperreactivity.

Food has been implicated in 19 patients (17.59\%) and the most common aggravating food was seafood, preserved and salty food. Food allergy and pseudoallergic reactions to food additives may have a role in some patients. Drugs account for a minority of chronic urticaria. However, it is common to see exacerbation of chronic urticaria caused by medication (29). In our study urticarial wheals and symptoms were exacerbated in $32.4 \%$ of the patients following the intake of non-steroidal anti-inflammatory drugs (NSAID). This is coincident with Sussman et al. (30) stating that up to 30 to $50 \%$ of CSU patients have exacerbations associated with NSAID ingestion. This could be due to a direct action of these drugs on mast cell degranulation as a result of inhibition of the cyclo-oxygenase pathway, which causes enhanced production of leukotrienes. In the current study, $80(74.1 \%)$ of the patients have normal laboratory investigations. The causes of $\mathrm{CU}$ still could not be identified. This is similar to the study of Kozel et al. (31) who 
suggested that there is no need for routine laboratory investigation, and history is the most important factor in identifying the causes of $\mathrm{CU}$. The urticaria severity score was divided into three groups: mild $(\leqslant 5)$, moderate $(6-$ $10)$, and severe $(>10)$ with a total mean \pm SD of $8.6 \pm 3.31$. In the present study, about half of the patients $(46.3 \%)$ showed moderate score, $(20.4 \%)$ of the patients had mild score, and (33.3\%) had severe score. This is consistent with another study done by Al-Hamamy et al. (12) in which about half of their patients showed moderate USS. However, this is in contrast to the results of Toubi et al. (32) who noticed that about half of their patients showed severe USS. These different results may be due to difference in severity of chronic urticaria among different people. In this study the frequency of ASST positive patients among patients with CU was $38 \%$. Those were consistent with other studies done by Asero et al. (33) who found that $35 \%$ of their patients had a positive ASST. A subsequent study done by Caproni et al. (34) reported that prevalence of ASST positivity in patients of chronic urticaria varies from $34 \%$ to $67 \%$. Those are a subset of patients with CU who have functional antibodies against the high affinity IgE receptor, or less commonly IgE. The prevalence difference according to the ethnic group of population suggests a genetic background for the disease (7). This study showed longer duration of chronic urticaria in patients with positive ASST. This is similar to that found in a study done by Abd El-Azim et al. (21). This could be explained by the difficulty in controlling chronic autoimmune urticaria. In contrast to this finding, George et al. (8) and Vikram Kumar et al. (19) found no significant difference in the duration of the disease between positive and negative ASST patients. A positive ASST has been associated with prolonged disease that is poorly responsive to routine therapy. One important advantage of ASST is to promote more tailored prognostic counseling. Hence, ASST is considered as a bedside clinical test which can detect the presence of autoimmunity in patients with CU (8). Nowadays, ASST is used to determine the need of autohemotherapy in treatment of some types of autoimmune chronic urticaria in the patients with positive one. There was insignificant difference between ASST positive and negative groups regarding age and the type of chronic urticaria. This finding was in agreement with that reported by Kulthanan et al. (29). Also in this study, the relationship between severity of symptoms (USS) and the positivity of the ASST was done. There was a highly statistically significant relation between severity of USS and positivity of ASST, indicating that chronic autoreactive urticaria patients have more severe symptoms that could not be controlled easily. This agrees with a study done by Caproni et al. (34) reporting that ASST positive patients had more widespread lesions and significantly more severe pruritus and systemic symptoms. This is in contrast to a study done by Al Hammamy et al. (12) and Lee et al. (16) showing that there were no statistically significant difference between ASST and the urticaria severity score. Serum anti IgE receptor antibody level was significantly higher in the ASST positive group in which $90.9 \%$ of the positive antibodies patients had positive ASST. There was a highly statistically significant relation between those antibodies and their mean \pm SD to the positive ASST patients $(\mathrm{p}=0.000)$. This explains the autoimmune nature. It is not affected by age of the patients, type, or duration of chronic urticaria. This result matched with other studies done by $(21,35)$ who found that serum IgE level was significantly increased in an ASST positive group in comparison to an ASST negative group. In conclusion, chronic urticaria is not an uncommon disease in our locality which represented $1.13 \%$ of our patients. Urticaria severity score and duration of urticaria was higher in positive ASST patients and hence the autoreactive type.

\section{Acknowledgments:}

This paper was extracted from a thesis done by the authors. The authors thank all staff members in the dermatology department, and the patients who participated in the study.

\section{Conflict of Interest:}

There is no conflict of interest to be declared.

Authors' contributions:

All authors contributed to this project and article equally. All authors read and approved the final manuscript.

\section{References:}

1) Ferrer M, Kaplan AP. Progress and Challenges in the Understanding of Chronic Urticaria. Allergy Asthma Clin Immunol. 2007; 3 (1): 31-5 doi: 10.2310/7480.2006.00016. PMID: 20525151, PMCID: PMC2873630.

2) Losol P, Yoo HS, Park HM. Molecular Genetic Mechanisms of Chronic Urticaria. Allergy Asthma Immunol Res. 2014; 6 (1): 13-21. doi: 10.4168/aair.2014.6.1.13. PMID: 24404388, PMCID: PMC3881394.

3) Maurer M, Bindslev-Jensen C, Gimenez-Arnau A, Godse K, Grattan CE, Hide M, et al. Chronic idiopathic urticaria (CIU) is no longer idiopathic: time for an update. Br J Dermatol. 2013; 168(2): 455-6. doi: 10.1111/j.1365-2133.2012.11171.x. PMID: 22835147. 
4) Khan DA. Chronic urticaria: Diagnosis and management. Allergy Asthma Proc. 2008; 29: 439-46. doi: 10.2500/aap.2008.29.3151. PMID: 18926051.

5) Kaplan AP. Treatment of Chronic Spontaneous Urticaria. Allergy Asthma Immunol Res. 2012; 4(6): 32631. doi: 10.4168/aair.2012.4.6.326. PMID: 23115728, PMCID: PMC3479225.

6) Criado PR, Criado RF, Maruta CW, Reis VM. Chronic urticaria in adults: state-of-the-art in the new millennium. An Bras Dermatol. 2015; 90(1): 74-89. doi: 10.1590/abd1806-4841.20153509. PMID: 25672302, PMCID: PMC4323701.

7) Abd El-Azim M, Abd El-Azim S. Chronic Autoimmune Urticaria: Frequency and Association With Immunological Markers. J Investig Allergol ClinImmunol. 2011; 21(7): 546-50.

8) George M, Balachandran C, Prabhu S. Chronic idiopathic urticaria: comparison of clinical features with positive autologous serum skin test. Indian J Dermatol Venereol Leprol. 2008; 74(2): 105-8. doi: 10.4103/0378-6323.39690. PMID: 18388365.

9) Asero R, Orsatti A, Tedeschi A, Lorini M. Autoimmune chronic urticaria associated with type 1 diabetes and Graves' disease. J Allergy ClinImmunol. 2005; 115: 1088-9. doi: 10.1016/j.jaci.2004.12.009. PMID: 15867871.

10) Confino-Cohen R, Chodick G, Shalev V, Leshno M, Kimhi O, Goldberg A. Chronic urticaria and autoimmunity: Associations found in a large population study. J Allergy ClinImmunol. 2012; 129: 130713. doi: 10.1016/j.jaci.2012.01.043. PMID: 22336078.

11) Greaves MW. Chronic idiopathic urticaria. Curr Opin Allergy ClinImmunol. 2003; 3(5): 363-8. doi: 10.1097/00130832-200310000-00008.

12) Al-Hamamy HR, Hameed AF, Abdulhadi AS. Autologous Serum Skin Test as a Diagnostic aid in Chronic Idiopathic Urticaria. ISRN Dermatol. 2013; 18: 291524. doi: 10.1155/2013/291524.

13) Al-Ahmad M, Alowayesh MS, Carroll NV. Economic burden of refractory chronic spontaneous urticaria on Kuwait's health system. Clinico Econ Outcomes Res. 2016; 8: 163-9 doi: 10.2147/CEOR.S98848. PMID: 27274290, PMCID: PMC4869626.

14) Krupa Shankar DS, Ramnane M, Rajouria EA. Etiological approach to chronic urticaria. Indian J Dermatol. 2010; 55: 33-8. doi: 10.4103/0019-5154.60348. PMID: 20418974, PMCID: PMC2856370.

15) Lapi F, Cassano N, Pegoraro V, Cataldo N, Heiman F, Cricelli I, et al. Epidemiology of chronic spontaneous urticaria: results from a nationwide, population-based study in Italy. Br J Dermatol. 2016; 174(5): 996-1004. doi: 10.1111/bjd.14470. PMID: 26872037.

16) Lee HC, Hong JB, Chu CY. Chronic Idiopathic Urticaria in Taiwan: A Clinical Study of Demographics, Aggravating Factors, Laboratory Findings, Serum Autoreactivity and Treatment Response. Journal of the Formosan Medical Association. 2011; 110(3): 175-82. doi: 10.1016/S0929-6646(11)60028-4.

17) Choi WS, Lim ES, Ban GY, Kim JH, Shin YS, Park HS, et al. Disease-specific impairment of the quality of life in adult patients with chronic spontaneous urticaria. Korean J Intern Med. 2018; 33(1): 185-92. doi: 10.3904/kjim.2015.195. PMID: 27243229 PMCID: PMC5768532.

18) Heng JK, Koh LJ, Toh MP, Aw DC. A study of treatment adherence and quality of life among adults with chronic urticaria in Singapore. Asia Pac Allergy. 2015; 5(4): 197-202. doi: 10.5415/apallergy.2015.5.4.197. PMID: 26539401, PMCID: PMC4630457.

19) Vikramkumar AG, Kuruvila S, Ganguly S. Autologous serum skin test as an indicator of chronic autoimmune urticaria in a tertiary care hospital in South India. Indian Dermatol Online J. 2014; 5:87-91. doi: 10.4103/2229-5178.146166. PMID: 25593814, PMCID: PMC4290187.

20) Ue AP, Souza PK, Rotta O, Furlani WJ, Lima AR, Sabbag DS. Quality of life assessment in patients with chronic urticaria. An Bras Dermatol. 2011; 86(5): 897-904. PMID: 22147026.

21) Abd El-Azim Z, El Mongy S, Salem H. Autologous Serum Skin Test in Chronic Idiopathic Urticaria: Comparative Study in Patients with Positive versus Negative Test. J Egypt Women Dermatol Soc. 2010; 7 : 129-33.

22) Vichyanond P, Sunthornchart S, Singhirannusorn V, Ruangrat S, Kaewsomboon S, Visitsunthorn N. Prevalence of asthma, allergic rhinitis and eczema among university students in Bangkok. Respir Med. 2002; 96: 34-8. doi: 10.1053/rmed.2001.1202. PMID: 11863208.

23) Yadav MK, Rishi JP, Nijawan S. Chronic urticaria and Helicobacter pylori. Indian J Med Sci. 2008; 62: 157-62. doi: 10.4103/0019-5359.40579.

24) Moreiraa A, Rodriguesa J, Delgadoa L, Fonsecaa J, Vaza M. Is Helicobacter pylori infection associated with chronic idiopathic urticaria? Allergol Immunopathol. 2003; 31(4): 209-14. doi: 10.1016/S03010546(03)79180-0. 
25) Criado PR, Criado RF, Maruta CW, Reis VM. Chronic urticaria in adults: state-of-the-art in the new millennium. An Bras Dermatol. 2015; 90(1): 74-89. doi: 10.1590/abd1806-4841.20153509. PMID: 25672302, PMCID: PMC4323701.

26) Bhatt TA. Chronic urticaria: Are hepatotropic viruses B\&C to blame? Egyptian Dermatology Online Journal. 2010; 7(1): 3.

27) Malik LM, Mufti S, Saeed S, Ahmed S, Hussain I. Hepatitis C seropositivity in patients with acute and chronic urticaria. Journal of Pakistan Association Dermatologist. 2008; 18: 144-8.

28) Dilek AR, Dilek N, Saral Y, Eks S. The role of protozoa in the etiology of chronic urticaria. Dermatologica Sinica. 2012; 30: 90-2. doi: 10.1016/j.dsi.2012.06.001.

29) Kulthanan K, Jiamton S, Thumpimukvatana N, Pinkaew S. Chronic idiopathic urticaria: prevalence and clinical course. J Dermatol. 2007; 34 (5): 294-301. doi: 10.1111/j.1346-8138.2007.00276.x. PMID: 17408437.

30) Sussman G, Hebert J, Gulliver W, Lynde C, Waserman S, Kanani A, et al. Insights and advances in chronic urticaria: a Canadian perspective. Allergy Asthma ClinImmunol. 2015; 11: 7. doi: 10.1186/s13223-0150072-2.

31) Kozel MM, Bossuyt PM, Mekkes JR, Bos JD. Laboratory tests and identified diagnoses in patients with physical and chronic urticaria and angioedema: A systemic review. J Am Acad Dermatol. 2003; 48: 40916. doi: 10.1067/mjd.2003.142. PMID: 12637921.

32) Toubi E, Kessel A, Avshovich N, Bamberger E, SaboE, Nusem D, et al. Clinical and laboratory parameters in predicting chronic urticaria duration: a prospective study of 139 patients. Allergy. 2004: 59: 869-73. doi: 10.1111/j.1398-9995.2004.00473.x. PMID: 15230821.

33) Asero R, Tedeschi A, Lorini M, Salimbeni R, Zanoletti T, Miadonna A. Chronic urticaria: novel clinical and serological aspects. Clin Exp Allergy. 2001; 31(7): 1105-10. doi: 10.1046/j.1365-2222.2001.01131.x. PMID: 11468002.

34) Caproni M, Volpi W, Giomi B, Cardinali C, Antiga E, Melani L, et al. Chronic idiopathic and chronic autoimmune urticaria: Clinical and immunopathological features of 68 subjects. Acta DermVenereol. 2004; 84: 288-90. doi: 10.1080/00015550410026939.

35) Kessel A, Helou W, Bamberger E, Sabo E, Nusem D, Panassof J, et al. Elevated serum total IgE--a potential marker for severe chronic urticaria. Int Arch Allergy Immunol. 2010; 153(3): 288-93. doi: 10.1159/000314370. PMID: 20484928. 